\title{
MENDELEY: UNTUK MENINGKATKAN KEMAMPUAN MENULIS DOSEN
}

\author{
Arizal N, Wita Dwika Listihana, Nofrizal \\ Universitas Lancang Kuning, Pekanbaru \\ arizall_n@yahoo.com
}

\begin{abstract}
In a successful college cannot be forgotten the existence of this one factor is the lecturer. Lecturers are the key to success in universities to educate students and students to be useful for the nation and the nation in the future. Some of the lecturers' duties include teaching, research and community service often mentioned by Tri Darma Perguruaan Tinggi. Of the three obligations of a lecturer is asked to have the ability to write skills such as Reports, Theses, Theses, Dissertations, Books, Articles and others. However, to be able to write well it is necessary to practice continuously and know the tools to write one is the tool for the citation and bibliography. Therefore required tools/applications that can help lecturers to write citations and bibliography. Mendeley is an application that can be used to write citations and bibliography, but not all lecturers can use this application. Methods to improve the ability to write lecturers do with several stages of lecture training materials/workshops about the contents of the introduction of Mendeley applications and videos about the ease of using this application, Practice using Mendeley application, Provide an opportunity for participants to ask questions or discussions about the material submitted, Conducting a survey to evaluate is done by spreading Pretest \& Posttest quizoner with success indicator of success level understanding of participants in this program is $80 \%$. The result of this activity proves that the lecturer can improve his writing ability is very positive for the development of lecturers expertise in making scientific research work.
\end{abstract}

Keywords: Quality of lecturer, Writing, Quote, References.

\begin{abstract}
Abstrak
Didalam perguruan tinggi yang sukses tidak bisa dilupakan adanya faktor yang satu ini yaitu dosen. Dosen merupakan kunci sukses dalam perguruan tinggi untuk mendidik mahasiswa dan mahasiswi agar dapat berguna bagi nusa dan bangsa dimasa yang akan datang. Beberapa tugas dosen diantaranya mengajar, penelitian dan pengabdian kepada masyarakat yang sering disebutkan dengan Tri Darma Perguruaan Tinggi. Dari tiga kewajiban seorang dosen tersebut dosen ditutut untuk memiliki kemampuan dalam menulis seperti Laporan, Skripsi, Tesis, Disertasi, Buku, Artikel dan lain-lain. Namun, untuk dapat menulis dengan baik maka perlu latihan secara terus menerus serta mengetahui alat bantu untuk menulis salah satunyanya adalah alat bantu untuk kutipan dan daftar pustaka. Oleh karena itu diperlukan alat/aplikasi yang dapat membantu dosen untuk menulis kutipan dan daftar pustaka. Mendeley merupakan aplikasi yang dapat digunakan untuk menulis kutipan dan daftar pustaka namun tidak seluruh dosen dapat menggunakan aplikasi ini. Metode dalam upaya untuk meningkatkan kemampuan menulis dosen lakukan dengan beberapa tahapan yaitu ceramah materi pelatihan/workshop tentang dengan isi yaitu pengenalan aplikasi Mendeley dan video tentang mudahnya menggunakan applikasi ini, Praktek menggunakan aplikasi Mendeley, Memberikan kesempatan kepada para peserta untuk mengajukan pertanyaan atau diskusi mengenai materi yang disampaikan, Melakukan survei untuk mengevaluasi dilakukan dengan cara menyebarkan kuisoner Pretest \& dan Posttest dengan Indikator keberhasilan kerberhasilan tingkat pemahaman peserta pada program ini adalah $70 \%$. Hasil dari kegiatan ini membuktikan bahwa tingkat pemahaman dosen $85 \%$ dapat meningkatkan kemampuan menulis kutipan dan daftar pustaka dan sangat positif bagi pengembangan keahlian dosen dalam membuat karya ilmiah.
\end{abstract}

Kata Kunci: Kualitas dosen, Menulis, Kutipan, Daftar Pustaka. 


\section{PENDAHULUAN}

Industri Perguruan tinggi tidak pernah lepas pada kemampuan menulis dosen-dosenya. Melalui kegiatan menulis, kemampuan seseorang dosen akan sangat mudah diketahui. Dalam urut keterampilan bahasa, menulis ditempatkan pada posisi terakhir, karena menurut beberapa penelitian menulis merupakan keterampilan berbahasa paling tinggi sekaligus paling langka digunakan dalam komunikasi(Anshori, 1996). Peran dosen yang dapat kita lihat ketika melakukan pembimbingan terhadap tugas akhir mahasiswa dosen mengarahkan mahasiswa menulis skripsi dalam bahasa Indonesia yang baik dan benar beserta detail penulisannya. (misalnya, spasi, titik, koma, dan sebagainya), dosen mengarahkan mahasiswa menulis proposal/skripsi sesuai pedoman yang berlaku (Haryati, 2012). Kemampuan menulis yang baik sangatlah penting bagi pembelajar kelak. Untuk mulai menulis, pembelajar bisa mulai dari sesuatu yang sederhana dan informal, misalnya jurnal/diari kegiatan seharihari (Santosa, 2002).

Fakultas Ekonomi merupakan salah satu fakultas yang dimiliki oleh Universitas Lancang Kuning pekanbaru saat ini fakultas ekonomi memiliki +50 orang dosen dengan hampir semua dosen sudah berijajah S3 dan S2 dan sebagian lagi sedang kuliah S3 dibeberapa kampus di Indonesia. Beberapa pelatihan-pelatihan yang diikuti oleh para dosen Fakultas Ekonomi terlihat dampak yang cukup berarti dimana sebagian dosen sudah menerapakan beberapa ilmunya di didalam proses pembelajaran sebagai contoh penerapan pada penulisan bahan ajar dan penulisan jurnal ilmiah untuk dipublikasi pada jurnal ilmiah baik sekala nasional maupun international.
Dari beberapa penelitian tentang workshop/pelatihan dari (Agusta, 2013) pelatihan memiliki pengaruh positif terhadap kinerja karyawan CV. Haragon Surabaya. Sedangkan menurut (Wahyudi, 2015) setelah dilakukan workshop kemampuan guru Kkg Gugus 02 Kecamatan Sumbermalang mengalami peningkatan. Pada penelitian yang dilakukan oleh (Siagian, 2015), (Ridwan, 2017) juga menunjukan dapat meningkatkan kemapuan kinerja karyawan.

Namun setelah dilakukan beberapa observasi dengan beberapa dosen tentang penulisan penelitian, bahan ajar dan artikel ilmiah masih banyak dari beberapa dosen di Fakultas Ekonomi yang belum memahami bagaimana membuat kutipan daftar pustaka/referensi dengan menggunakan sistem aplikasi komputer, selama ini masih menggunakan sistem manual. Persoalan ini tentu sangat penting untuk di cari solusinya, karena tuntutan didunia publikasi karya ilmiah pada saat ini khususnya jurnal-jurnal yang sudah memiliki akreditasi $\mathrm{A} / \mathrm{B}$ dan jurnal intenational sudah wajib untuk menggunakan aplikasi khusus sebagai syarat agar lulus dan diterima pada jurnal-jurnal tersebut. Mendeley merupakan aplikasi popular yang digunakan sebagai pengelolah daftar pustaka dengan 2.8 juta pengguna dan 535 juta dokumen(Costas, Zahedi, \& Wouters, 2015). Menurut (Fairclough \& Thelwall, 2015) mendeley dapat menjadi media untuk membagai artikel kepada orang lain dan dapat mudah untuk digunakan dalam mengutip untuk mendukung penelitan. Mendeley juga dapat menjadi cara untuk meningkatkan dampak artikel dengan cara mengutipnya dengan menggunakan mendeleyn (Mohammadi, Thelwall, Haustein, \& Larivi??re, 2015). 
Arizal, dkk. Mendeley: Untuk Meningkatkan Kemampuan...

\section{METODE PELAKSANAAN}

Dalam rangka menyelesaikan permasalah diatas maka dilakukan dengan metode yang sistematis dengan langkah-langkah sebagai berikut :

(1)Ceramah materi pelatihan/workshop tentang :

(a)Pengenalan aplikasi Mendeley

(b)Video tentang mudahnya menggunakan applikasi ini

(2)Praktek menggunkan aplikasi Mendeley dengan tahapan-tahapan sebagai berikut:

(a)Registrasi akun Mendeley (Buka situs web http://www.mendeley.com)

(b)Menginstall aplikasi Mendeley pada KomputerMembuat referensi menggunakan Mendeley

(3)Sesi pertanyaan atau diskusi mengenai materi yang disampaikan

(4)Evaluasi dilakukan dengan cara menyebarkan kuisoner Pretest \& dan Post- test

(5)Indikator kerberhasilan tingkat pemahaman peserta pada program ini adalah $70 \%$ dari materi yang diberikan setelah dilakukan evaluasi menggunakan Pretest \& Post tes.

\section{HASIL DAN PEMBAHASAN}

Sebelum kegiatan workshop dilakukan, kegiatan diawali dengan menyebarkan undangan kepada perserta yang terdiri dari pimpinan dan Dosendosen dilingkungan Fakultas Ekonomi Universitas Lancang Kuning. Hasil dari penyebaran undangan kepada peserta disambut dengan atusias oleh para peserta hal ini dapat terlihat pada tingkat kehadiran dari peserta pada saat workshop dilaksanakan, dengan memberikan tanggapan dan Tanyajawab untuk agar semakin bagus tingkat pemahaman peserta.
Didalam kegiatan peningkatan pemahaman dosen tentang membuat daftar pustaka dan kutipan dengan menggunakan aplikasi mendeley dijelaskan tahapan-tahapan dalam menggunakan mendeley yaitu sebagai berikut:

(1)Registasi sebagai member/dengan cara create account

Masukkan First name, Last name, Email, dan Password yang diinginkan lalu klik tombol Get started.

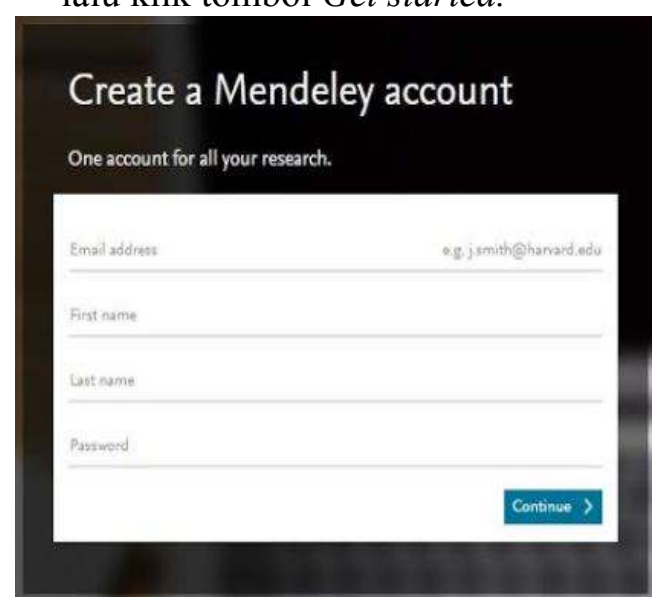

Gambar 1: Create Mendeley Account Sumber:(Nofrizal, 2017)

(2)Lalu pilih bidang studi dan status akademis, dan klik Finish

Hi Perbanas . Let's complete your profile.

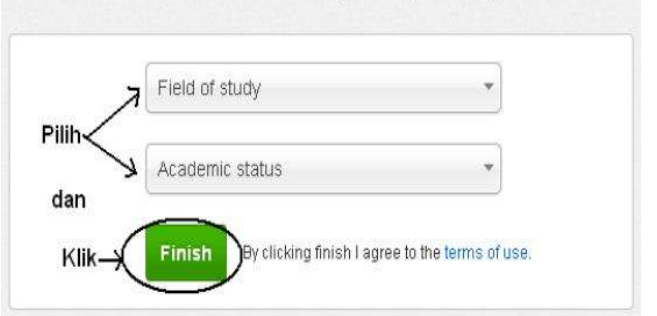

Gambar 2: Lets complete your profile Sumber:(Nofrizal, 2017)

(3)Secara otomatis akan muncul tampilan di bawah ini, kemudian klik Save File, tunggu hingga selesai proses downloadnya 


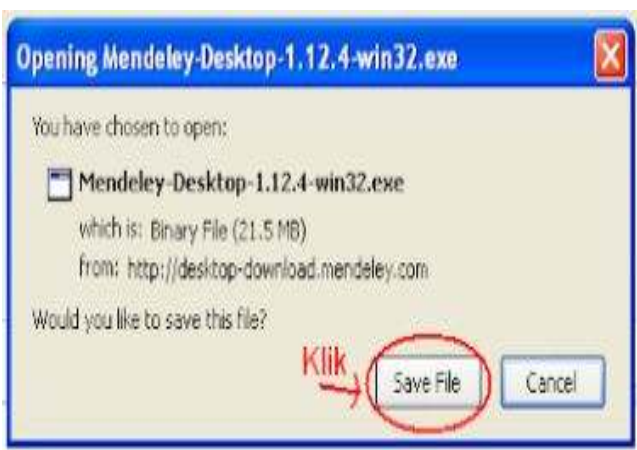

Gambar 3: File download

Sumber:(Nofrizal, 2017)

(4)Tahap pendaftaran selesai, Anda akan dikirimkan email dari Mendeley ke alamat email yang Anda daftarkan tadi.

(5)Masuk ke email yang Anda daftarkan, buka email dari Mendeley dengan subject Please confirm your e-mail address:

(6)Klik Verify E-mail Address untuk menjalankan proses verifikasi email Anda, maka selesailah proses registasi dan unduh/download

\section{ㅇำ MENDELEY}

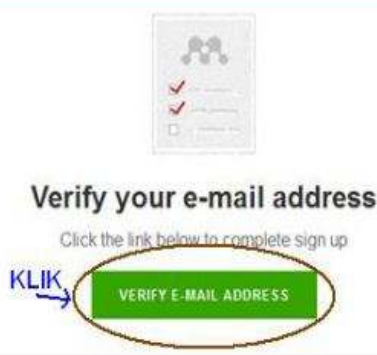

Gambar 4: Verify E-mail Address

Sumber:(Nofrizal, 2017)

(7)Tahapan selanjutnya adalah install dan cara menggunakan mendeley, klik aplikasi mendeley yang sudah unduh di folder download

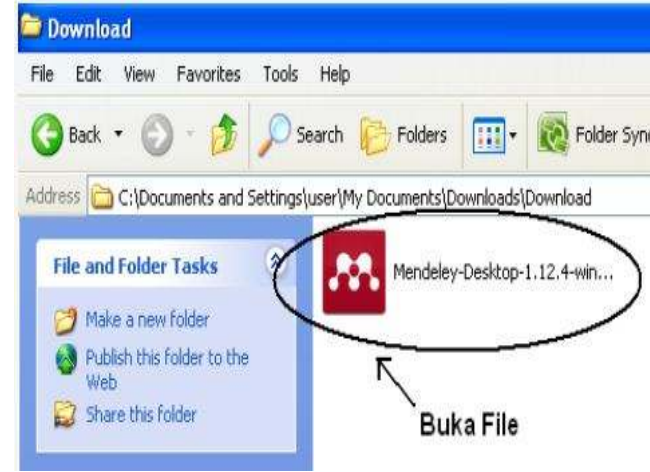

Gambar 5: Install dan cara menggunakan mendeley Sumber:(Nofrizal, 2017)

(8)Setelah aplikasi Mendeley Desktop terinstall, jalankan aplikasi tersebut dengan mengeklik icon Mendeley di Desktop Anda.

(9)Saat pertama kali aplikasi dijalankan, aplikasi akan meminta credential account Mendeley Anda. Masukkan alamat email dan password account Mendeley yang sudah Anda daftarkan sebelumnya.

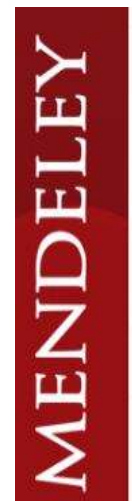
Welcome to Mendeley

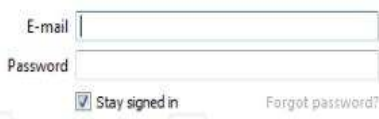

Gambar 6: Install dan cara menggunakan mendeley Sumber:(Nofrizal, 2017)

(10)Masuk ke menu Tools, ,lalu pilih Install MS Word Plugin 


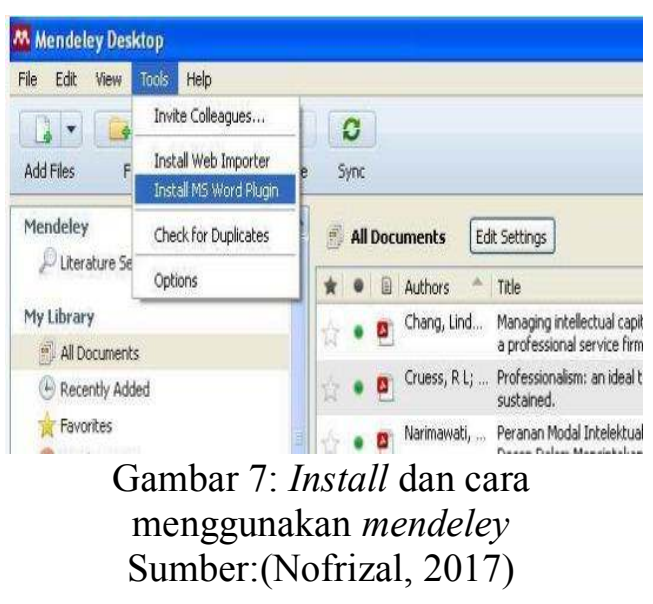

Tujuan dari intall ini adalah agar muncul aplikasi ini di MS Word computer, sehingga dapat mempermudah proses pengutipan dan daftar pustaka

(11) Berikut tampilan Mendeley pada MS Word (menu References) anda

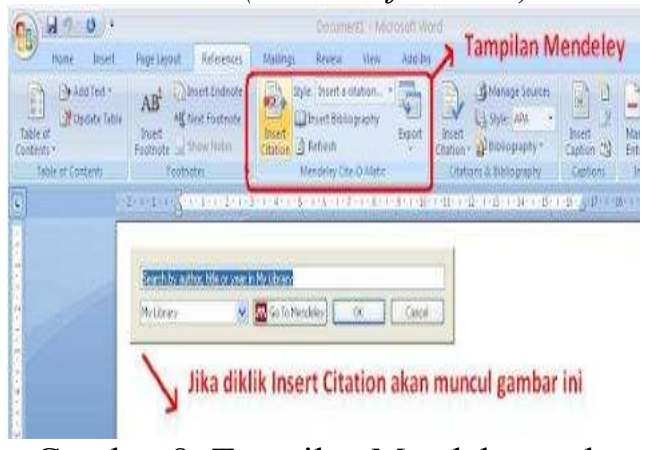

Gambar 8: Tampilan Mendeley pada Ms.Word Sumber:(Nofrizal, 2017)

(12) Selanjutnya, cara menggunakan mendeley untuk kutipan dan daftar pustaka silahkan tambah jurnal yang akan di kutip dengan cara add files pada toolbar mendele, setelah itu

(13) Untuk membuat sumber kutipan, buka file jurnal yang sedang Anda buat (format word). Lalu klik References, dan pilih Insert Citation (tahap 1), kemudian muncul pilihan (tahap 2). Lalu ketik pada kolom "Search by author, title or year in My Library" referensi yang anda gunakan pada kutipan tersebut. Klik OK!

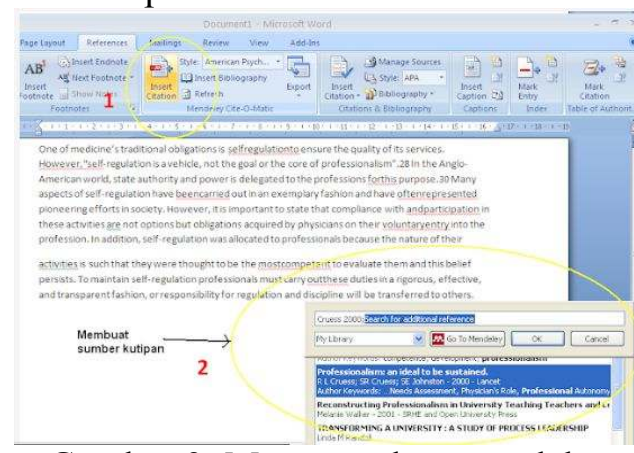

Gambar 9: Menggunakan mendeley untuk kutipan dan daftar pustaka

(Nofrizal, 2017)

(14)Untuk membuat daftar pustaka, klik Insert Bibliography pada References:

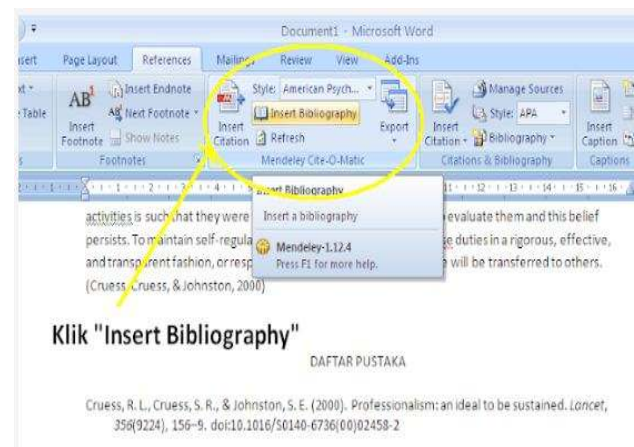

Gambar 10: Insert Bibliography pada References (Nofrizal, 2017)

Kuisioner terdiri dari beberapa pertayaan tentang topik mendeley. Tujuan dari dibuatnya kuisioner ini adalah untuk mengetahui sejauh mana manfaat dan tingkat pengetahuan peserta tentang topik sebelum dan sesudah kegiatan ini dilaksanakan. Dengan mengetahui hasil dari kuisioer maka tim akan melakukan evaluasi sejauh mana dampak dari ini sehingga dikemudian hari dapat dilakukan perbaikan. Adapun hasil dari kuisioner yang disebarkan kepada peserta dapat dilihat tabel 1 dibawah ini.

\section{Tabel 1. Hasil Pretest dan Postest Workshop Aplikasi Mendeley}




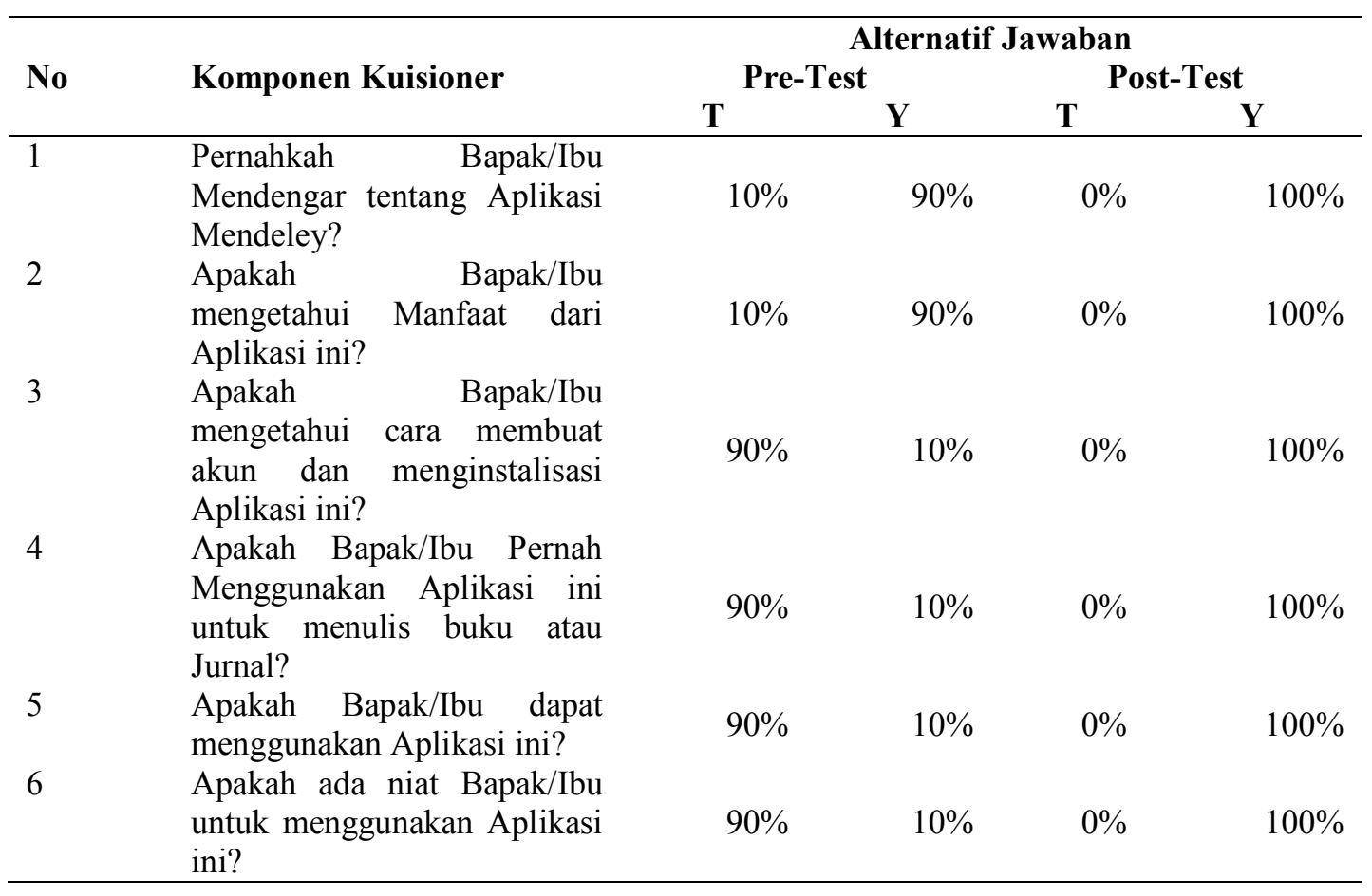

Ket: $\mathrm{T}=$ Tidak dan $\mathrm{Y}=\mathrm{Ya}$

Sumber: (Data Olahan, 2018)

Dari rekapitulasi kuisioner diatas maka dapat diketahui bahwa terjadi peningkatan pengetahuan peserta kegiatan workshop aplikasi mendeley dimana peserta yang pada awalnya hanya $10 \%$ saja yang mengetahui menjadi $90 \%$ mengetahui dan memahami. Sedangkan pengetahuan mengenai pemanfaatan aplikasi mendeley meningkat menjadi $100 \%$, dari awalnya hanya $90 \%$ saja yang mengetahuinya. Sedangkan $100 \%$ peserta mengetahui dan memahami proses aplikasi mendely melalui praktek langsung yang didampingi oleh tim pelaksana kegiatan pengabdian. Dan $100 \%$ peserta kegiatan pengabdian berminat untuk menggunakan aplikasi mendeley untuk membuat karya ilmiah.

\section{SIMPULAN}

Kegiatan terlaksana sesuai dengan tujuan dan rencana yang sudah ditetapkan. Pada penyelenggaraan kegiatan ini dapat diketahui bahwa ada peningkatan pengetahuan peserta mengenai Aplikasi Mendeley untuk membuat refrensi/ citation. Kegiatan ini sangat efektif dalam penerapan ilmu pengetahuan dan teknologi bagi masyarakat khususnya para dosen Fakultas Ekonomi. Dengan proses yang sederhana, workshop ini dapat memberikan nilai pengetahuan terutama dalam dosen ketika ingin membuat jurnal/ buku ajar dan Modul. Berdasarkan pengamatan yang diperoleh dari kegiatan ini, maka perlu dilanjutkan dengan pembinaan yang berkesinambungan dan memberi pembekalan bukan hanya kepada dosen tetapi juga kepada mahasiswa khususnya Fakultas Ekonomi Universitas Lancang Kuning 
Arizal, dkk. Mendeley: Untuk Meningkatkan Kemampuan...

DAFTAR PUSTAKA

Agusta, L. (2013). Pengaruh pelatihan dan motivasi kerja terhadap kinerja karyawan CV Haragon Surabaya. Agora, 1(3).

Anshori, D. S. (1996). Peningkatan Kemampuan Menulis Mahasiswa Melalui Model Workshop dalam Perkuliahan Kepenulisan pada Program Nonkependidikan Jurusan Pendidikan Bahasa dan Sastra Indonesia FPBS UPI. Action Research, 5.

Costas, R., Zahedi, Z., \& Wouters, P. (2015). Do "altmetrics" correlate with citations? Extensive comparison of altmetric indicators with citations from a multidisciplinary perspective. Journal of the Association for Information Science and Technology, 66(10).

Fairclough, R., \& Thelwall, M. (2015). National research impact indicators from Mendeley readers. Journal of Informetrics, 9(4).

Haryati, R. (2012). Survey kinerja dosen pembimbing skripsi dan kualitas skripsi mahasiswa akuntansi stie malangkucecwara. Jurnal Dinamika Akuntansi, 4(2).
Mohammadi, E., Thelwall, M., Haustein, S., \& Larivi??re, V. (2015). Who reads research articles? An altmetrics analysis of Mendeley user categories. Journal of the Association for Information Science and Technology, 66(9).

Nofrizal. (2017). Cara Menggunakan Mendeley Untuk Daftar Pustaka dan Referensi. Retrieved March 10, 2018.

Ridwan, A. S. S. (2017). Peningkatan Mutu Dikalangan Guru Sd Dengan Kemampuan Penyusunan Proposal Ptk. Jurnal Penjaminan Mutu, 3(1).

Santosa, M. H. (2002). Pemanfaatan Blog (Jurnal Online) Dalam Pembelajaran Menulis. Universitas Pendidikan Ganesha,.

Siagian, S. S. I. 1. (2015). Pengaruh Pelatihan, Kepuasan Kompensasi, Motivasi Dan Disiplin Kerja Terhadap Kinerja Karyawan. Jurnal Ilmu Dan Riset Manajemen, 4(9).

Wahyudi, I. (2015). Meningkatkan kemampuan guru dalam menyusun tes hasil belajar akhir semester melalui workshop di $\mathrm{kkg}$ gugus 02 kecamatan sumbermalang tahun 2014/2015. Pancaran, 5(1). 